\title{
Pressupostos da complexidade no ensino de ciência e tecnologia: um estudo de caso em um curso de bacharelado em ciência e tecnologia
}

\author{
Assumptions of complexity in science and technology teaching: a case study in a bachelor \\ degree in science and technology academic degree
}

\author{
MACÊDO, Luiz C.A. ${ }^{1}$ \\ NEVES, Marcos C.D. ${ }^{2}$ \\ MELLO, Débora A.T. ${ }^{3}$
}

Resumo

Este trabalho tem como objetivo avaliar o ensino segundo os ideais da complexidade definidos por Edgar Morim. Para isso, definimos um conjunto de pressupostos da complexidade para analisar documentos que embasam um curso superior de Bacharelado em Ciência e Tecnologia. Nosso estudo de caso aponta tendências de ensino com complexidade no curso, contudo, esse fato não é o suficiente para garantir que o ensino neste curso atenda aos ideais da complexidade.

Palavras-chave: ensino de ciência e tecnologia. teoria da complexidade. pensamento complexo. currículo.

\begin{abstract}
This work aims to evaluate teaching according to the ideals of complexity defined by Edgar Morim. For that, we defined a set of complexity assumptions to analyze documents that support a Bachelor's degree in Science and Technology. Our case study points to teaching trends with complexity in the course, however, this fact is not enough to ensure that teaching in this course meets the ideals of complexity. Keywords: science and technology teaching. complexity theory. complex thinking. curriculum.
\end{abstract}

\section{Introdução}

Não há como contestarmos a importância da Ciência e da Tecnologia (C\&T) em nossa sociedade atual e nem como imaginarmos um futuro sem a presença de C\&T, pois estão imbricadas em nosso modo de ser. Corroboramos com Hobsbawm (2003) quando este afirma que a sociedade após as grandes guerras do século XX viveu uma ascensão científica e tecnológica nunca vista em tão curto período de tempo de forma que o modelo linear de desenvolvimento, que pregava que mais ciência gera mais tecnologia que por sua vez gera mais

\footnotetext{
${ }^{1}$ Aluno, Doutornado no Programa de Pós Graduação em Ensino de Ciência e Tecnologia (PPGECT) da UTFPR. Docente em UFERSA, departamento de Ciência e Tecnologia. Universidade Tecnológica Fderal do Paraná. luizcarlos@ufersa.edu.br

2 Professor Doutor Programa de Doutorado em Ensino de Ciência e Tecnologia (PPGECT). Docente Universidade Estadual de Maringá, departamento Ensino de Física. macedane@yahoo.com

${ }_{3}^{3}$ Aluna, Doutornada no Programa de Pós Graduação em Ensino de Ciência e Tecnologia (PPGECT) da UTFPR. datmello@gmail.com
} 
riquezas que resulta em mais bem-estar social, parecia ser uma verdade inquestionável. Acontece que nos anos de 1970 essa verdade foi questionada pelo movimento Ciência, Tecnologia e Sociedade (CTS), pois tínhamos muito mais ciência e tecnologia e não percebíamos um maior bem estar social, mas sim maior aumento da degradação no ambiente e na saúde humana (PALÁCIOS; GALBARTE; BAZZO, 2005).

A ciência aplicada, que se materializa na tecnologia, traz grandes impactos a sociedade nas suas diversas dimensões. Dias Sobrinho (2014) destaca o consumismo, as desigualdades socioeconômicas, a poluição, os desmatamentos e as tecnologias bélicas como impactos da C\&T que ameaçam de alguma forma a vida em nosso planeta. Frente a isso, o movimento CTS aponta a necessidade de se compreender a ciência quanto seus impactos na sociedade e de tentar formar um cidadão crítico, consciente, capaz de refletir e tomar decisões quanto às questões que envolvam a C\&T na busca de minimizar e resolver os problemas socioambientais atuais (AULER, DELIZOCOV, 2001).

O ensino de ciências no Brasil evolui ao longo do século XX, na qual saímos de um ensino de ciências caracterizado pela transmissão do conhecimento científico de cunho Behaviorista e especialista (KRASILCHICK, 1992) para um ensino de ciências com concepção construtivista, perspectiva crítica, com preocupações ambientais, consolidação da perspectiva CTS e preocupações humanísticas (CACHAPUZ et al., 2005).

No Brasil, as engenharias são classificadas como cursos de tecnologias, na qual tem como objetivo proporcionar uma formação de base científica para serem aplicadas em ramos da atividade humana (OLIVEIRA, 2002). O ensino nas engenharias também já teve uma concepção altamente especialista com forte base científica e técnica, mas, como nos traz os autores Bazzo, Pereira e Lisinger (2016), este ensino nos dias atuais deve ser capaz de fornecer mais que a formação técnica de qualidade, com o rigor científico necessário, devendo adicionar a visão social, crítica e criativa a esta formação.

Dessa forma, podemos perceber que tanto o ensino de ciência quanto o da tecnologia apresentam tendências evolutivas a ser um ensino na qual o conteúdo científico deve ser relacionado com outros aspectos dos saberes para que, com isso, possa haver um melhor entendimento sobre os problemas atuais, em especial os de cunho socioambientais. Diante disso, entendemos a abordagem da complexidade do Francês Edgard Morin (1921 ) como alternativa possível a este ensino, uma vez que a própria abordagem de ensino com CTS, dependendo da forma de como será trabalhada, tende a complexidade (MACÊDO; 2020).

Além das engenharias como representante dos cursos tecnológicos, temos os cursos de Bacharelado em Ciência e Tecnologia (BCT), que são cursos inovadores oriundos do Programa de Restruturação e Expansão das Universidades Federias Brasileiras (REUNI) caracterizados como Bacharelados Interdisciplinares que tem por objetivo serem cursos de graduação de natureza geral de formação de competências, habilidades, conhecimentos gerais e básicos em grandes áreas do conhecimento (BRASIL, 2009).

Diante disso, o objetivo deste trabalho é o de avaliar em um curso de BCT específico elementos que possam indicar o quanto este tende ao ensino com concepções da complexidade, o que chamamos de pressupostos da complexidade. Para isso, vamos apresentar na seção 2 as concepções de uma ciência complexa; na seção 3 uma discussão sobre o currículo complexo e a definição dos pressupostos da complexidade para o currículo; na seção 4 apresentaremos a metodologia deste trabalho e os documentos analisados; na seção 5 a síntese dos dados coletados e as análises; e as considerações finais na seção 6 .

\section{A Concepção de Ciência Complexa}

A ciência se destaca de outras formas do conhecimento pelo seu método de obtenção do conhecimento, técnicas, estrutura do saber, produtos, reconhecimento e valorização do saber por parte da comunidade científica, o que atesta a esse conhecimento um alto grau de certeza (CHIBENI, 2004). A ciência pode ser do tipo 
fundamental, quando busca a explicação do real e do tipo aplicada, quando busca o controle sobre o real (MORAIS, 2009).

As críticas à ciência são inúmeras, embora por vezes relevadas a perspectiva filosófica e não tratadas pela própria ciência. Destas, destacamos: Feyerabend (1989), Chalmers e Fiker (1993) que questionam o método científico quanto à veracidade das afirmações científicas obtidas a partir deste e apontam para a questão de que as grandes descobertas da ciência não foram realizadas a partir de um método; Kuhn (1997), Neves (2002) e Vasconcellos (2012) vão por em xeque a crença na verdade científica e na comunidade que validam e aceitam determinado conhecimento em detrimento a outros; e Logan (2012) vai questionar o fato da ciência buscar e valorizar as explicações mais simples, lógica e racional para os fenômenos.

Tais questionamentos foram objetos de estudos do Morin, que dedica boa parte de seu trabalho na busca por uma nova ciência, uma ciência capaz de superar os problemas da ciência clássica e ir além, no que ele chamou de ciência complexa. Morin busca criar um método para esta nova ciência através de sua Teoria da Complexidade, que emerge a partir de conhecimentos da ciência tradicional. Em síntese, podemos descrever que essa teoria tem como base a Teoria dos Sistemas, que defende a ideia de que tudo que conhecemos são sistemas; a Teoria da Cibernética, que estuda as formas de organizações das coisas e fenômenos; e a Teoria da Informação, na qual estuda as comunicações de uma organização com o meio na qual esta faz parte (MORIN, 2005).

A complexidade é definida por Morin como:

a um primeiro olhar, a complexidade é um tecido (complexus: o que é tecido junto) de constituintes heterogêneas inseparavelmente associadas: ela coloca o paradoxo do uno ao múltiplo. Num segundo momento, a complexidade é efetivamente o tecido de acontecimentos, ações, interações, retroações, determinações, acasos que constituem nosso mundo fenomênico (MORIN, 2011, p.13).

Ou seja, a ideia do simples nessa concepção de conhecer é substituída pelo complexo. A ciência complexa deve basear-se também em um método de obtenção que permita um conhecer mais próximo do real, na qual considera o objeto ou fenômeno estudado como um sistema, composto por diversas partes e como parte de outros sistemas, com uma organização variando entre estados de organizado, em desorganização e caóticos em meio a um ambiente na qual se comunicam e interagem, sendo dependente deste quanto a sua autonomia, onde a certeza é apenas parte do conhecimento assim como a incerteza e o acaso também são.

Morin não consegue estabelecer um método que garantisse tal forma de obtenção do conhecimento, ele também reconhece a validade do conhecimento científico, embora o considere como um conhecimento reduzido, descontextualizado e fragmentado quanto sua organização do saber, as disciplinas da ciência, defendendo a necessidade de métodos, instrumentos, operadores e conceitos que possibilitem a religação dos saberes para obter um conhecimento mais próximo do real, complexo, estabelecendo então uma forma de pensar (MORIN, 1998). Disso, Morin propõe o pensamento complexo, que seria sua resposta ao método cartesiano da ciência clássica, uma forma de pensar capaz de ligar os conhecimentos dispersos, contextualizalos e globaliza-los na busca do saber mais próximo do real. Pois,

a inteligência parcelar, compartimentada, mecânica, disjuntiva, reducionista, quebra o complexo do mundo, produz fragmentos, fraciona os problemas, separa o que é ligado, unidimensionaliza o multidimensional. Trata-se de uma inteligência ao mesmo tempo míope, presbita, daltônica, zarolha. Elimina na casca todas as possibilidades de compreensão e de reflexão, matando assim todas as chances de julgamento corretivo ou de visão a longo termo. Quanto mais os problemas se tomam multidimensionais, mais há incapacidade para pensar essa multidimensionalidade; quanto mais a crise avança, mais progride a incapacidade de pensá-la; quanto mais os problemas se tomam planetários, mais 
se tornam impensados. Incapaz de considerar o contexto e o complexo planetário, a inteligência cega produz inconsciência e irresponsabilidade (MORIN, 2013, p.14).

Morin atribui a incompreensão dos grandes problemas às características do saber científico clássico e aponta o pensamento complexo como uma nova forma de aprender ciência que possibilita a compreensão dos problemas complexos. Como problemas de natureza complexa, Roso e Auler (2016) citam: a questão da energia, mudanças climáticas, consumismo, poluição, mobilidade, sustentabilidade dentre outros na qual os conhecimentos especialistas em apenas um campo disciplinar não proporcionam uma melhor compreensão. Questões desta natureza exigem que o objeto ou fenômeno sejam trabalhados de forma sistêmica quanto a sua formação e suas interações, devendo ser abordado nas várias dimensões dos saberes de forma inter ou transdisciplinar, exigindo do sujeito a capacidade de organização desse conhecimento e de sua representação. Tais características podem ser trabalhadas pela abordagem da complexidade.

Para chegarmos ao pensamento complexo sobre um determinado fenômeno ou objeto, Morin (2003; 2008) elenca os seguintes preceitos: necessidade de contextualização local, global, temporal e histórico; ligação do conhecimento do todo com as partes e suas relações com o ambiente; consideração das relações de causalidade complexa e as interações internas e externas frente a questão da organização e seus estados organizacionais; consideração do acaso e da incerteza; incorporação da subjetividade do conhecimento e atenção ao fato do conhecimento ser histórico e cultural, propenso a erros; a busca pela dialógica do saber, na qual saberes concorrentes e antagônicos devem estarem vinculados. Dessa forma, o conhecimento complexo,

[...] incita a distinguir e fazer comunicar em vez de isolar e separar, a reconhecer os traços singulares, originais, históricos do fenômeno em vez de ligá-los pura e simplesmente às determinações e leis gerais, a conceber a unidade/multiplicidade de toda entidade em vez de a heterogeneizar em categorias separadas ou a homogeneizar em indistinta totalidade. Incita a da conta dos caracteres multidimensionais de toda realidade estudada (MORIN, 2008, p.334).

\section{O Currículo Complexo}

O currículo é uma forma de organização do conhecimento. Nele temos as perspectivas de como deve ocorrer o processo de ensino, as concepções e o que deve ser ensinado, sendo o documento que guia o processo de ensino, podendo refletir as concepções sociais que se deseja reproduzir na sociedade. Silva (2005) nos traz que o currículo pode ser classificado como: Tradicional, quando apresenta uma proposta de ensino neutra, baseado nas concepções mecânicas de aprendizado onde os saberes são repassados pelos professores e memorizados pelos alunos; Crítico, que traz a concepção marxista para o aprendizado, refletindo a luta de classes e o papel da educação como fator redutor das desigualdades sociais, sendo questionador frente a realidade atual; e do tipo Pós-Crítico, refletindo a concepção pós-moderna para o ensino, valorizando a subjetividade, o multiculturalismo e a realidade social do sujeito questionando e relativizando os saberes. Este autor também destaca que nenhum currículo é neutro e que todos terão uma intencionalidade ao ato de educar.

As ideias do Morin, já discutidas, trazem muito da concepção Pós-Moderna, Morin é um pós-moderno na ciência e uma educação baseada na complexidade poderia implementar muitas de suas concepções no currículo. Os currículos nas concepções tradicional e crítica apresentam sintonia com o modelo racional-positivista por trazerem o como características básicas a homogeneidade, unidimensionalidade, normatividade, sequencialidade, previsibilidade e disciplinaridade, citam Ribeiro, Veloso e Zanardi (2016), que também nos alerta que os currículos pós-modernos, normalmente, são propostas muito vagas, preocupadas mais com a exaltação filosófica do pós-modernismo do que com a questão pedagógica, sendo de difícil execução. 
Um Projeto Político Pedagógico (PPP) pode ser entendido como um documento que contém a reflexão sobre a intencionalidade da educação que deve ser provida por uma instituição de ensino (VEIGA, 2006). O PPP é uma exigência da Lei de Diretrizes e Bases da Educação (LDB) de 1996 às instituições de ensino e no ensino superior vai caracterizá-lo, as vezes, como Projeto Político-Pedagógico do Curso (PPC), sendo obrigatório a cada curso ofertado por uma instituição de ensino, que deve refletir:

[...] um conjunto de conhecimentos, saberes, competências, habilidades, experiências, vivências e valores organizados de forma integrada visando a formação de profissionais competentes e cidadãos, para uma sociedade contextualizada num determinado tempo e espaço histórico, político, econômico e social (MASETO, 2011, p.4).

Sendo assim, o que seria um currículo complexo? Podemos então pressupor que seria um currículo baseado nos ideais da complexidade, trazendo em suas determinações elementos da complexidade. Saxe (2009) nos traz que um currículo complexo deve apresentar as relações entre as unidades de aprendizagem, com estratégias que permitam a continuidade do conhecimento, tendo como objetivo instigar o aluno para o pensamento complexo, fugindo da perspectiva disciplinar, fragmentada e descontextualizada do saber. Souza (2011) defende como currículo complexo um currículo mutável e instável que integre os múltiplos aspectos da educação, sendo autoorganizado e inovador e que promova a motivação para o aprender.

Um projeto de currículo com concepções da complexidade é o da Universidade Federal do Paraná (UFPR) Campus Litoral, que traz sua organização baseada no Conhecer e Compreender, onde o aluno é estimulado a conhecer de forma critica a realidade do conhecimento que está sendo submetido; Compreender e Propor, que se relaciona a relação entre a teoria e a prática; e Propor e Agir, na qual o aluno deve relacionar os conhecimentos obtidos em sua futura vida profissional (UFPR LITORAL, 2008).

Partindo das reflexões sobre a complexidade do Morin e sua importância no ensino de ciências e das concepções sobre o currículo com ideais da complexidade, elencamos os seguintes pressupostos como elementos que, estando presente no currículo, poderão favorecer ao aprendizado complexo:

1) Promoção do diálogo entre os saberes: a busca de um saber sistêmico, de cunho inter ou trans disciplinar, promovendo a superação do modelo disciplinar de ensino;

2) Favorecimento do espírito investigativo do aluno: despertar o aluno para a necessidade de aprendizagem, um aprender a aprender, de modo a incentivá-lo a construção do saber mais elaborado que o especialista;

3) Promoção do pensamento crítico e incentivo à criatividade: o pensamento crítico pode ajudar na formação de pontos de vista sobre um determinado assunto, favorecendo a busca da pluralidade do saber. Da criatividade emerge o subjetivismo, que pode levar a construções de soluções mais elaboradas, ajudando na questão do enfrentamento da incerteza;

4) Promoção da busca do conhecimento em outras fontes de saber: esse ponto, embora possa parecer obvio nos dias de hoje, deve representar as múltiplas visões e profundidade sobre um determinado assunto, ações que possibilitam a ampliação do saber a ser apreendido e desenvolvido no aluno por diversas fontes do conhecimento;

5) O trabalho com a questão da verdade do conhecimento científico (epistemologia da ciência): este ponto refere-se a epistemologia da ciência, do questionamento frente a esta como verdade absoluta. Tal questionamento favorece a ampliação do saber, na busca constante por conhecimento nas várias dimensões do saber, possibilitando manter a mente aberta quanto a necessidade de agregar novos conhecimentos; 
6) O trabalho com a incerteza: a incerteza deve fazer parte do conhecimento complexo, promovendo a busca de um conhecimento mais amplo sobre o objeto ou fenômeno, suas relações e possibilidades;

7) Promoção do trabalho com a dialógica (saberes antagônicos): o incentivo ao trabalho de síntese de conhecimentos mesmo que estes sejam opostos, antagônicos, na busca de suas relações e implicações na ampliação dos saberes.

\section{Metodologia}

A metodologia deste trabalho pode ser classificada segundo Gil (2008) como uma pesquisa aplicada, de nível exploratório, do tipo estudo de caso com abordagem qualitativa. Para isso, analisamos o PPC do curso BCT da Universidade Federal Rural do Semi-Árido (UFERSA) Campus Caraúbas e outros documentos que o embasam, descrevendo-os abaixo. A técnica de coleta de dados teve como base a análise de conteúdo de Bardin (2011), na qual os dados foram agrupados em categorias, os pressupostos da complexidade por nós definidos e analisados qualitativamente compondo as inferências. A coleta dos dados nos documentos oficiais embasa a cientificidade necessária a este trabalho, conforme defende Richardson (2015).

Quanto aos documentos na qual coletamos os dados temos o Parecer CNE/CES 1362 de 2001 (BRASIL, 2001), um documento elaborado pelo Conselho Nacional de Educação (CNE) em sua Câmara de Ensino Superior (CES) na qual apresenta um texto base para a elaboração da DCN para os cursos de Engenharias. Seu texto é rico em entendimentos sobre a necessidade de uma nova educação superior para a engenharia, trazendo uma crítica aos cursos de engenharia quanto à necessidade de reformulação deste em atendimento as novas exigências social e de mercado. Este documento é um reflexo da Lei de Diretrizes e Bases da Educação (LDB) de 1996, que traz concepções do Banco Mundial e UNESCO sobre a necessidade de uma educação para uma nova sociedade, a Sociedade do Conhecimento, conforme Macêdo (2020).

A partir do Parecer 1362/2001 surge a Diretriz Curricular Nacional (DCN) 11 de 2002 (BRASIL, 2002), o documento oficial que embasa a construção dos PPC para as engenharias, no qual também estaremos buscando dados para nossa análise. Nele temos a descrição do perfil que o engenheiro deve ter, as competências e habilidades desejadas a esse profissional e o currículo desejado a formação. Diferentemente do Parecer 1362/2001, este documento é de caráter mais técnico, não trazendo texto que justifica seu conteúdo, mas detalhando aspectos do ensino que os cursos devem implementar.

O principal documento que levantamos dados, objeto central do nosso estudo, é o currículo do curso de Bacharelado em Ciência e Tecnologia, que se materializa no PPC e data do ano de 2010, sendo uma proposta de ensino que pode se caracteriza como um currículo do tipo crítico (UFERSA, 2010). O PPC apresenta o curso do BCT como um Bacharelado Interdisciplinar, definindo-o como:

[...] uma modalidade de curso de graduação, e se caracteriza por agregar uma formação geral em diversas áreas do conhecimento humano, e um aprofundamento num dado campo do saber, promovendo o desenvolvimento de competências e habilidades que possibilitarão ao egresso a aquisição de ferramentas cognitivas que conferem autonomia para a aprendizagem ao longo da vida bem como uma inserção mais plena na vida social, em todas as suas dimensões (UFERSA, 2010, p.2).

Embora este curso não se intitule como uma engenharia, pois é um curso generalista na grande área da Ciência e Tecnologia, é uma graduação na qual após o término o aluno pode fazer outra graduação complementar em uma das engenharias ofertada pela instituição e apresenta as concepções curriculares, didáticas e pedagógicas tendo como referência explicita a DCN 11/2002. 


\section{Análise dos Dados}

Aqui apresentamos uma síntese dos dados colhidos no processo de análise de conteúdo nos documentos e a análise destes sobre o aspecto de cada um dos pressupostos da complexidade elencados para o currículo.

\subsection{Promoção do diálogo entre os saberes}

Temos no Quadro 1 os principais destaques que apontam para a atenção ao pressuposto que julgamos atender a questão do incentivo ao diálogo entre os saberes.

\section{Quadro 1}

Destaque da promoção do diálogo entre saberes.

\begin{tabular}{|l|l|}
\hline Documento & Pontos destacados \\
\hline Parecer n. 1362/2001 & $\begin{array}{l}\text { Necessidade de nova formação para o mercado de trabalho, onde "o novo engenheiro deve } \\
\text { ser capaz de propor soluções que sejam não apenas tecnicamente corretas. Ele deve ter a } \\
\text { ambição de considerar os problemas em sua totalidade, em sua inserção numa cadeia de } \\
\text { causas e efeitos de múltiplas dimensões" (BRASIL, 2001, p.01), há um destaque para a } \\
\text { necessidade de uma formação transdisciplinar que considere a "[...] preocupação com a } \\
\text { valorização do ser humano e preservação do meio ambiente, integração social e política } \\
\text { do profissional” (BRASIL, 2001, p.01), e que, para isso, o currículo deve prever ações que } \\
\text { promovam “a compreensão totalizante do conhecimento pelo estudante" (BRASIL, 2001, } \\
\text { p.02). }\end{array}$ \\
\hline DCN 11/2002 & $\begin{array}{l}\text { Sobre a formação, descreve que esta deva ser “[...] generalista, humanista, crítica e } \\
\text { reflexiva, capacitada a absorver e desenvolver novas tecnologias, estimulando a sua } \\
\text { atuação crítica e criativa na identificação e resolução de problemas, considerando seus } \\
\text { aspectos políticos, econômicos, sociais, ambientais e culturais, com visão ética e } \\
\text { humanística, em atendimento às demandas da sociedade" (BRASIL, 2002, p.1). }\end{array}$ \\
\hline PPC do BCT & $\begin{array}{l}\text { Traz referências a LDB-1996, na qual explicita que "Introdução das Diretrizes Curriculares, } \\
\text { flexibilização curricular, mobilidade acadêmica, enfoque sistêmico e interdisciplinar, } \\
\text { criação dos ciclos básico e profissional, entre outros" (UFERS, 2010, p.8), e na justificativa } \\
\text { do curso quanto ao currículo, ressaltando que "é necessário que os atuais currículos de } \\
\text { cursos de graduação se tornem mais flexíveis e interdisciplinares" (UFERSA, 2010, p.3). }\end{array}$ \\
\hline
\end{tabular}

Fonte: baseado em Macêdo (2020) todos os grifos de nossa autoria.

Podemos perceber que o Parecer 1362/2001 está alinhado a questão da promoção de um saber além do disciplinar, um saber sistêmico, preocupado com as questões de uma formação que supere a técnica especialista. A DCN 11/2002 vai refletir essas concepções de forma mais técnicas e sem a justificativa para isso, apresentando a necessidade de um aprendizado que reflita os diversos aspectos dos saberes como ideais formativos do engenheiro, na qual o PPC do BCT deve também contemplar. O PPC do BCT estabelece a questão da interdisciplinaridade como ideal pedagógico e destaca o enfoque sistêmico do saber, embora este apresente uma estrutura disciplinar fortemente atrelada as exigências da DCN 11/2002 quanto as disciplinas curriculares, ficando a questão interdisciplinar como estratégia pedagógica. Essa questão da estratégia pedagógica interdisciplinar e do enfoque sistêmico pode ser trabalhada no PPC na exigência curricular de atividades extras, prevendo 90 horas para isso, que podem ser de natureza extensionista e/ou de pesquisa e o trabalho de conclusão de curso com 60 horas previstas como créditos a serem cumpridos pelos alunos (UFERSA, 2010). 


\subsection{Favorecimento do espírito investigativo do aluno}

Destacamos no Quadro 2 as passagens que remetem ao favorecimento do espirito investigativo do aluno.

\section{Quadro 2}

Destaque da promoção do espirito investigativo

\begin{tabular}{|l|l|}
\hline Documento & \multicolumn{1}{|c|}{ Pontos destacados } \\
\hline $\begin{array}{l}\text { Parecer n. } \\
\mathbf{1 3 6 2 / 2 0 0 1}\end{array}$ & $\begin{array}{l}\text { Temos a referência a investigação científica quanto às "atividades complementares, tais como } \\
\text { trabalhos de iniciação científica, projetos multidisciplinares, visitas teóricas, trabalhos em equipe, } \\
\text { desenvolvimento de protótipos, monitorias, participação em empresas juniores e outras atividades } \\
\text { empreendedoras" (BRASIL, 2001, p.2). }\end{array}$ \\
\hline $\mathbf{D C N} \mathbf{1 1 / 2 0 0 2}$ & $\begin{array}{l}\text { Repete o mesmo texto do Parecer 1362/2001, e em seu artigo 5o e destaca a questão da } \\
\text { competência e habilidades desejadas ao engenheiro como a de "projetar e conduzir experimentos } \\
\text { e interpretar resultados" (BRASIL, 2002, p.1). }\end{array}$ \\
\hline PPC do BCT & $\begin{array}{l}\text { Além de estabelecer na grade curricular horas de atividades extras e do TCC, temos a referência } \\
\text { aos projetos de iniciação científica e atividades de pesquisa e extensão, na qual destaca o incentivo } \\
\text { as ações extras curriculares através de "programas de bolsas de estudos de iniciação científica são } \\
\text { concedidos a um significativo número de alunos que desenvolvem pesquisas com orientação } \\
\text { individual de professor e apresentam resultados em seminário anual de iniciação científica" } \\
\text { (UFERSA, 2010, p.27). }\end{array}$ \\
\hline
\end{tabular}

Fonte: baseado em Macêdo (2020) todos os grifos de nossa autoria

O Parecer 1362/2001 destaca a importância do incentivo a investigação científica através de outras atividades, atividades extras, na qual o texto se repete no documento da DCN 11/2002 e que também estabelece a capacidade de projetar e conduzir experimentos e interpretar dados como uma atividade desejada ao engenheiro. O PPC do BCT reflete as diretivas de incentivo a investigação científica através das atividades extras curriculares, prevista no currículo, em especial as atividades de iniciação científica, onde destaca incentivo com bolsas de estudo, e da necessidade de um TCC ao formando, que é uma atividade obrigatória de investigação científica.

\subsection{Promoção do pensamento crítico e da criatividade}

O Quadro 3 apresenta os principais destaques que apontam para a questão da promoção do pensamento crítico e da criatividade nos alunos.

Dessa forma, embora seja destacado a concepção desejada do perfil do formando a atender uma formação crítico e criativo, não há em nenhum dos documentos quaisquer especificações sobre como isso pode ser alcançado, ensinado, ficando as palavras apenas representando um desejo de formação ao futuro profissional. 


\section{Quadro 3}

Destaque da promoção do pensamento crítico e da criatividade

\section{Documento \\ Parecer n. 1362/2001 \\ DCN 11/2002 \\ (BRASIL, 2002, p.1, grifo nosso)}

PPC do BCT

\section{Pontos destacados}

Definição do perfil do egresso nas engenharias como "O perfil dos egressos de um curso de engenharia compreenderá uma sólida formação técnico científico e profissional geral que o capacite a absorver e desenvolver novas tecnologias, estimulando a sua atuação crítica e criativa na identificação e resolução de problemas, considerando seus aspectos políticos, econômicos, sociais, ambientais e culturais, com visão ética e humanística, em atendimento às demandas da sociedade" (BRASIL, 2001, p.4).

Repete a definição do egresso do Parecer1362/2001 quanto a definição do egresso, também destaca a necessidade da crítica quanto a avaliação de sistema, na qual o engenheiro deve "avaliar criticamente a operação e a manutenção de sistemas" na descrição das competências e habilidades (BRASIL, 2002, p.1)

Justifica a necessidade de uma formação crítica onde o curso deve "oferecer uma formação melhor, mais cidadã, mais crítica e com mais qualidade aos nossos estudantes, para atender aos anseios da população brasileira e das necessidades do mercado de trabalho, foi criado um novo modelo de formação universitária [...]" (UFERSA, 2010, p.1, grifo nosso), repete o mesmo texto do Parecer n.1362/2001 e quanto a DCN n. 11/2002 no que se refere a definição do egresso, destacando quanto ao perfil desejado ao bacharelando em C\&T como: "O curso de Bacharelado em Ciência e Tecnologia tem como perfil do formando egresso/profissional o bacharel, com formação generalista, humanista, crítica e reflexiva, capacitado a absorver e desenvolver novas tecnologias, estimulando a sua atuação crítica e criativa na identificação e resolução de problemas, considerando seus aspectos políticos, econômicos, sociais, ambientais, culturais, com visão ética e humanística, em atendimento às demandas da sociedade" (UFERSA, 2010, p.9).

Fonte: baseado em Macêdo (2020) todos os grifos de nossa autoria.

\subsection{Busca do conhecimento em outras fontes do saber}

Entendemos a busca do conhecimento em outras fontes dos saberes como a busca fora da especialidade técnico científico estabelecido no currículo formativo. O Quadro 4 vai nos trazer as concepções nos documentos que favorecem a busca do conhecimento em outras fontes do saber, muito embora esse item não fora encontrado explicitamente em nenhuma passagem na análise dos documentos.

Assim, embora não haja menções diretas a necessidade da busca de informação em diversas fontes dos saberes, podemos entender que há essa necessidade, pois é uma característica desejável ao engenheiro ter outros conhecimentos e que este saiba como relacioná-los ao conhecimento técnico especialista. 
Quadro 4

Busca do conhecimento em outras fontes do saber

\begin{tabular}{|c|c|}
\hline Documento & Pontos destacados \\
\hline Parecer n. 1362/2001 & $\begin{array}{l}\text { Neste documento temos a questão da relação do saber em suas múltiplas dimensões do saber, } \\
\text { destacando a necessidade do novo engenheiro ser capaz de "[...] propor soluções que sejam } \\
\text { não apenas tecnicamente corretas, ele deve ter a ambição de considerar os problemas em sua } \\
\text { totalidade, em sua inserção numa cadeia de causas e efeitos de múltiplas dimensões" isso leva } \\
\text { a necessidade de conhecimento nas várias dimensões do saber (BRASIL, 2001, p.1). }\end{array}$ \\
\hline $\begin{array}{l}\text { DCN 11/2002 } \\
\text { (BRASIL, 2002, p.1, } \\
\text { grifo nosso) }\end{array}$ & $\begin{array}{l}\text { Não temos referência direta a outras fontes do saber, mas na passagem: "avaliar o impacto } \\
\text { das atividades da engenharia no contexto social e ambiental", podemos relacionar como um } \\
\text { desejo da busca do conhecimento técnico e seus impactos em outros contextos (BRASIL, 2002, } \\
\text { p.01) }\end{array}$ \\
\hline PPC do BCT & $\begin{array}{l}\text { No currículo do BCT, também não encontramos referência diretas a questão da busca do } \\
\text { conhecimento em outras fontes do saber, mas sim a reflexão da necessidade do conhecimento } \\
\text { em suas múltiplas dimensões, temos que " [..] o processo avaliativo deverá proporcionar aos } \\
\text { alunos a possibilidade de manifestação dos conhecimentos produzidos, das condutas, } \\
\text { competências e habilidades desenvolvidas [...] avaliação da aprendizagem objetiva auxiliar o } \\
\text { aluno a compreender o grau de amadurecimento em seu processo de formação, } \\
\text { especialmente no que concerne ao desenvolvimento de competências e à apropriação dos } \\
\text { conhecimentos significativos para atuação profissional" que demonstra a necessidade da } \\
\text { busca dos saberes além dos técnicos disciplinares (UFERSA, 2010, p.22, grifo nosso). }\end{array}$ \\
\hline
\end{tabular}

Fonte: baseado em Macêdo (2020) todos os grifos de nossa autoria.

\subsection{Trabalho com a questão da verdade do conhecimento científica}

Neste quesito, não encontramos nada nos documentos do Parecer 1362/2001 e na DCN 11/2002 que pudéssemos relacionar a esse pressuposto. No PPC do BCT (UFERSA, 2010) temos uma disciplina de Filosofia da Ciência e Metodologia Científica que pode vir a discutir isso, mas devido a carga horária para esta disciplina ser de 60 horas, acreditamos que fica difícil trabalhar de forma consistente esse tema com os alunos, uma vez que a disciplina na realidade é a composição de duas em uma: Filosofia da Ciência e Metodologia Científica.

\subsection{O trabalho com a incerteza}

Neste quesito, também não encontramos nada nos documentos do Parecer 1362/2001 e na DCN 11/2002 11/2002 que pudéssemos relacionar a esse pressuposto diretamente. No PPC do BCT temos a referência a questão da necessidade de um "aprendizado ao longo da vida" (UFERSA, 2010, p.09) que, ao nosso entender, se relaciona com a questão do enfrentamento da incerteza, pois ao se deparar com uma situação o futuro formando deve ser capaz de estuda-la, propor soluções e aprender sobre em uma concepção voltada a resolução de problemas de ordem especialista da formação do engenheiro.

\subsection{Promoção do trabalho com a dialógica (saberes antagônicos)}

Neste quesito, também não encontramos nada nos documentos do Parecer 1362/2001, na DCN 11/2002 e no PPC do BCT que pudéssemos relacionar a esse pressuposto diretamente. Porém, entendemos que o fato destes documentos darem ênfase a perspectiva crítica do saber como desejado a formação do engenheiro, já citamos acima isso na perspectiva crítica, e a de que a criticidade possa ser trabalhada através do debate de ideias contraditórias, consideramos que existe a possibilidade de que haja o atendimento a esse pressuposto. Mas isso dependeria da questão da pedagogia trabalhada no ensino, ficando a cargo do professor o trabalho nessa perspectiva. 


\section{Considerações sobre a análise de documentos}

O Parecer 1362/2001 se mostra como um documento mais idealista e alinhado ideais da complexidade, embora seu texto seja curto, podemos encontrar nele palavras como "totalidade", "causa e efeitos", "múltiplas dimensões" e "transdisciplinaridade" que nos remete a ideais da complexidade.

Já a DCN 11/2002 é um documento com característica mais técnica no qual podemos visualizar o aspecto tecnicista, como se a complexidade idealizada no Parecer 1362/2001 tivesse sido adaptada para o tecnicismo em um texto que deixa claro a necessidade de formar cidadãos para uma melhor eficiência da aplicação do conhecimento científico a serviço do capital.

O PPC do BCT implementa diretamente a DCN 11/2002, se configurando como um texto mais denso por trazer a descrição de estratégias didáticas e detalhamentos sobre a estrutura organizacional e o conteúdo curricular do curso a ser trabalhado para que o formando possa apresentar característica desejáveis à formação em acordo com as competências e habilidades desejadas.

Nossa análise nos documentos sobre os pressupostos da complexidade está resumida no Quadro 5. Usamos a seguinte classificação: Atende, em relação ao atendimento ao pressuposto analisado; desatende, ao não atendimento; e provável quando há uma possibilidade de atendimento ao pressuposto analisado.

Quadro 5

atenção aos pressupostos pelos documentos analisados

\begin{tabular}{|l|l|l|l|}
\hline \multicolumn{1}{|c|}{ Pressupostos da Complexidade } & PPC & DCN 11/2002 & Parecer1362/2001 \\
\hline Promoção do diálogo entre os saberes; & Atende & Desatende & Atende \\
\hline $\begin{array}{l}\text { Favorecimento do espírito investigativo do } \\
\text { aluno; }\end{array}$ & Atende & Provável & Atende \\
\hline $\begin{array}{l}\text { Promoção do pensamento crítico e } \\
\text { incentivo à criatividade; }\end{array}$ & Provável & Provável & Provável \\
\hline $\begin{array}{l}\text { Promoção da busca do conhecimento em } \\
\text { outras fontes de saber; }\end{array}$ & Provável & Provável & Provável \\
\hline $\begin{array}{l}\text { Trabalhar a questão da verdade do } \\
\text { conhecimento científico (epistemologia da } \\
\text { ciência); }\end{array}$ & Provável & Desatende & Desatende \\
\hline $\begin{array}{l}\text { O trabalho com a incerteza; } \\
\begin{array}{l}\text { Promoção do trabalho com a dialógica } \\
\text { (saberes antagônicos); }\end{array}\end{array} \quad$ Provável & Desatende & Desatende \\
\hline
\end{tabular}

Fonte: baseado em Macêdo (2020).

Sobre o Quadro 5, temos os quatro primeiros pressupostos atendido ou provavelmente atendidos nos documentos. No caso da materialização no ensino, o PPC do BCT, a estratégia para atender a promoção para o diálogo entre os saberes, a interdisciplinaridade e o incentivo ao espírito investigativo do aluno é a de criar no currículo um espaço para isso, uma carga horária específica para atividades extras curriculares e em especial a obrigatoriedade do TCC; a promoção do pensamento crítico e criativo fica apenas nas determinações curriculares, que poderão ser ou não trabalhadas pelos professores nas disciplinas assim como a busca do conhecimento em outras fontes do saber; quanto ao pressuposto da promoção do diálogo entre os saberes e o favorecimento do espirito investigativo do aluno, estes ficam apenas como determinação pedagógica, na qual o professor pode ou não trabalhar em sua didática; os pressupostos de trabalho com a verdade do conhecimento científico, o trabalho com a incerteza são pressupostos característicos a uma ciência pós-moderna, como o currículo do BCT traz com concepção a ciência positivista, tais aspectos não são contemplados de forma explicita, mas podem ser trabalhados em disciplinas específicas prevista no currículo do BCT; a questão da promoção do 
trabalho com dialógica, no conceito da complexidade, não é previsto nos documentos, mas pode ser trabalhada em estratégias pedagógicas no ensino.

O currículo do BCT é do tipo crítico, estrutura do saber disciplinar, mas podemos destacar a importância das horas previstas para as atividades extras e o potencial destas como elementos para um ensino mais alinhado a complexidade, que pode quebrar a disciplinaridade do currículo, dando a abertura para um ensino com concepções da complexidade. Outro ponto que merece destaque é a questão de encontrarmos pressupostos da complexidade expressos na forma de competências e habilidades nos documentos oficiais. Isso mostra a importância dos ideais da complexidade para o ensino de C\&T assim como também reflete os anseios do capital para a necessidade de uma melhor formação, onde os profissionais devem ter a capacidade de desempenharem melhor suas funções em um mercado de trabalho cada vez mais exigente em uma sociedade econômica do conhecimento na qual a educação e a C\&T se unem em uma política de mercados competitivos mundiais, pressionando cada vez mais o ensino, exigências estas também constatada em Ramos (2016).

\section{Considerações finais}

Temos que os documentos analisados refletem a tendência de evolução no ensino de ciência e tecnologia na qual a concepção especialista técnica é desejada juntamente com outros aspectos dos saberes em uma relação que permeia os ideais da complexidade para o ensino de ciências. Entendemos que a educação em Ciência e Tecnologia é determinante para a construção de uma nova sociedade, corrigir os erros do passado e buscar a construção de uma sociedade mais justa e democrática quanto a C\&T também deve ser papel da educação superior. Defendemos aqui a complexidade do Morin como uma abordagem viável a essa nova concepção de ensino de ciências e mostramos alguns aspectos da complexidade expressos como pressupostos que podem ajudar a verificar indícios da complexidade presentes em documentos oficiais e no currículo.

O currículo do BCT analisado é do tipo crítico com concepções de ciência positivista, apesar de apresentar tendências a complexidade herdadas de documentos anteriores na qual balizam a criação deste, vai relevar essa questão para a sua materialização, a execução, onde vários dos pressupostos da complexidade por nós definidos dependerão do ato pedagógico, a mercê dos docentes. Dessa forma, é possível que elementos de uma ciência complexa e do pensamento complexo do Morin estejam presentes no aprendizado dos alunos deste curso, sendo necessário um estudo mais profundo para verificar essa questão.

Isso mostra também a importância do currículo em deixar explicito os conteúdos, os procedimentos, os valores desejados no ato do ensino e de prever a capacitação docente para sua realização, este último aspecto não presente no currículo estudado. Tais importâncias são refletidas em Zabala (1998) que defende que o processo de ensino de ciencias deve envolver os conteúdos, os métodos, as normas e valores que permeiam o conteúdo a ser ensinado. Nosso estudo conclui que um ensino mais voltado para a complexidade vai depender dos valores que os professores vão trazer consigo, sendo importante a questão da capacitação do docente para isso, uma vez que o professor tende a ensinar reproduzindo a forma de como aprendeu (MORAES, 1996). Disso, concluímos que o ensino no curso do BCT da UFERSA pode ser complexo na medida em que os professores estejam familiarizados com os ideais da complexidade, mesmo que elementos da complexidade estejam presentes no currículo.

\section{Referências bibliográficas}

Auler, D., \& Delizoicov, D. (2001). Alfabetização científico-tecnológica para quê?. Ensaio Pesquisa em Educação em Ciências (Belo Horizonte), 3(2), 122-134.

Bardln, L. (2011). Análise de conteúdo. Lisboa: edições, 70, 225. 
Bazzo, W. A., von Lisingen, I., \& do Vale Pereira, L. T. (2016). Educação tecnológica: enfoques para o ensino de engenharia. Ed. UFSC.

Brasil. Ministério da Educação (2009). REUNI: Programa de Apoio a Planos de Reestruturação e Expansão das Universidades Federais Reuni 2008: Relatório de Primeiro Ano. Brasília: MEC/SESU.

Brasil (2001). Parecer CNE/CES n. 1362, de 12 de dezembro de 2001. Diretrizes Curriculares Nacionais dos Cursos de Engenharia. Disponível em: http://portal.mec.gov.br/cne/arquivos/pdf/CES1362.pdf. Acesso em: 12 mar. 2020.

Brasil (2002). Resolução CNE/CES n. 11/2002, de 11 de março de 2002. Institui Diretrizes Curriculares Nacionais do Curso de Graduação em Engenharia. Disponível em: http://portal.mec.gov.br/cne/arquivos/pdf/CES112002.pdf. Acesso em: 2 abr. 2020.

Cachapuz, A., Gil-Perez, D., Carvalho, A. D., Praia, J., \& Vilches, A. (2005). A necessária renovação do ensino das ciências. São Paulo: Cortez.

Chalmers, A. F., \& Fiker, R. (1993). O que é ciência afinal?. São Paulo: Brasiliense.

Chibeni, S. S. (2004). O que é ciência. Campinas: Unicamp.

Dias Sobrinho, J. (2014). Universidade e novos modos de produção, circulação e aplicação do conhecimento. Avaliação: Revista da Avaliação da Educação Superior (Campinas), 19(3), 643-662.

Feyerabend, P. (1989). Contra o método: esboço de uma teoria anárquica da teoria do conhecimento. Rio de Janeiro (RJ): Francisco Alves.

Gil, A. C. (2008). Métodos e técnicas de pesquisa social. 6. ed. Ediitora Atlas SA.

Hobsbawm, E. (2003). Era dos extremos: o breve século XX. Editora Companhia das Letras.

Krasilchik, M. (1992). Caminhos do ensino de ciências no Brasil. Em Aberto, 11(55).

Kuhn, T. S. (1997). A estrutura das revoluções científicas. Editora Perspectiva SA.

Logan, R. K. (2012). Que é informação? Rio de Janeiro: Contraponto.

Macêdo, L.C.A (2020). Pressupostos da Complexidade no Ensino de Ciência e Tecnologia: Um estudo de caso no curso de bacharelado em ciência e tecnologia. Tese de Doutorado. Universidade Tecnológica Federal do Paraná.

Masetto, M. T. (2011). Inovação curricular no ensino superior. Revista e-curriculum, 7(2).

Moraes, M. C. (2008). O paradigma educacional emergente: implicações na formação do professor e nas práticas pedagógicas. Em aberto, 16(70).

Morin, E. (2010). A religação dos saberes: o desafio do século XXI. In A religação dos saberes: o desafio do século XXI. Bertrand Brasil.

Morin, E. (2003). Da necessidade de um pensamento complexo. Para navegar no século XXI, Rio de Janeiro: Garamond.

Morin, E. (2005). O método 1: a natureza da natureza. Sulina.

Morin, E. (2008). Ciencia com consciência. Rio de Janeiro: Bertrand, 11. 
Morin, E. (2011). Introdução ao pensamento complexo. Porto Alegre: Sulina, 4.

Morin, E. (2013). A via para o futuro da humanidade. Rio de Janeiro: Bertrand-Brasil.

Neves, M. C. D. (2002). Lições da escuridão ou revisitando velhos fantasmas do fazer e do ensinar ciência. Campinas, São Paulo: Mercado de Letras.

Oliveira, M. B (2002). A ciência que queremos e a mercantilização da universidade. In: Tempos de greve na universidade pública. Marília (SP), Unesp Publicações. p.17-41.

Palacios, E. M. G., Galbarte, J. C. G., \& Bazzo, W. (2005). Introdução aos estudos CTS (Ciencia, Tecnología e Sociedade). Organización de Estados Iberoamericanos (OEI).

Ramos, L. O. L (2016). O lugar da interdisciplinaridade na educação superior: uma análise dos projetos pedagógicos dos Cursos de Bacharelado Interdisciplinar da UFBA. Tese (Doutorado em Educação) Universidade Federal da Bahia.

Ribeiro, M. P.; Veloso, S. G. A.; Zanardi, T. A. C (2016). Fim da teoria crítica? Crítica aos extremos pós-modernos e pós-estruturais da teoria curricular. Currículo sem Fronteiras, 16(2), 255-282.

Richardson, R. J (2015). Pesquisa social: métodos e técnicas. São Paulo: atlas.

Roso, C. C., \& Auler, D. (2016). A participação na construção do currículo: práticas educativas vinculadas ao movimento CTS. Ciência \& Educação (Bauru), 22(2), 371-389.

Saxe, E. B. (2009). Diseño curricular: de la integración a la complejidad/Curriculum design: from integration to complexity. Actualidades Investigativas en Educación, 9(2).

Tadeu, T. (2005). Documentos de identidade: uma introdução às teorias do currículo. Autêntica.

Sousa, J. M. (2011). Um modelo complexo do ato educativo. Da Autonomia da escola ao sucesso educativo, Lisboa: Cosmos, 215-228.

UFERSA (Universidade Federal Rural do Semi-Árido) (2010). Projeto Pedagógico do Curso Interdisciplinar em Ciência e Tecnologia. Mossoró (RN), 2019. Disponível em: https://cet.ufersa.edu.br/wpcontent/uploads/sites/28/2019/08/PPC_CeT_2019.pdf. Acesso em: 7 mar. 2020.

UFPR LITORAL (Universidade Federal do Paraná. Litoral) (2008). Projeto Político Pedagógico. Matinhos (PR): UFPR. Disponível em: http://www.litoral.ufpr.br/portal/wp-content/uploads/2015/02/PPP-UFPRLITORAL_Set-2008_Alteracao_Dez-2008.pdf. Acesso em: 12 abr. 2019.

Vasconcellos, M. J. E. (2012). Pensamento sistêmico: o novo paradigma da ciência. Papirus Editora.

Veiga, I. P. A. (2006). Perspectivas para reflexão em torno do projeto político-pedagógico. Escola: espaço do projeto político-pedagógico, 17, 09-32.

Zabala, A. (1998). A prática educativa: como ensinar. Porto Alegre: Artmed.

Esta obra está bajo una Licencia Creative Commons Attribución-NoCommercial 4.0 International

(cc) EY-NC 